\title{
Pascal Josephe, La société immédiate
}

Paris, Calmann-Lévy, 2008, 247 p.

\section{Gilles Boenisch}

\section{(2) OpenEdition}

\section{Journals}

Édition électronique

URL : http://journals.openedition.org/questionsdecommunication/1673

DOI : 10.4000/questionsdecommunication. 1673

ISSN : 2259-8901

\section{Éditeur}

Presses universitaires de Lorraine

\section{Édition imprimée}

Date de publication : 1 décembre 2008

Pagination : 415-416

ISBN : 978-2-86480-981-4

ISSN : 1633-5961

\section{Référence électronique}

Gilles Boenisch, «Pascal Josephe, La société immédiate », Questions de communication [En ligne], 14 |

2008, mis en ligne le 25 janvier 2012, consulté le 22 septembre 2020. URL : http://

journals.openedition.org/questionsdecommunication/1673; DOI : https://doi.org/10.4000/

questionsdecommunication. 1673

Ce document a été généré automatiquement le 22 septembre 2020

Tous droits réservés 


\title{
Pascal Josephe, La société immédiate
}

\author{
Paris, Calmann-Lévy, 2008, 247 p.
}

\author{
Gilles Boenisch
}

\section{RÉFÉRENCE}

Pascal Josephe, La société immédiate, Paris, Calmann-Lévy, 2008, 247 p.

1 Pascal Josèphe, spécialiste des médias et ancien directeur des programmes de plusieurs chaînes de télévision, reconverti dans la veille technologique et le conseil, signe son premier ouvrage sur la singularité des médias numériques. À juste titre, il explique qu'une des révolutions majeures à laquelle ils participent réside dans un rythme imposé qui relève de « l'immédiateté ». De cette caractéristique découle, pour l'auteur, des modes de communication qui bouleversent et mettent en péril l'ensemble du fonctionnement social.

2 Dans une première partie (pp. 17-46), Pascal Josèphe retrace l'histoire des médias en tant que catalyseurs des évolutions sociales. Passant de l'imprimé aux mass media, du postmodernisme aux neurosciences, pour aboutir à «l'homo numericus» (p. 73) pressenti par Nicholas Negroponte (L'Homme numérique, Paris, Éd. Pocket, 1997), le livre tente d'explorer le contexte de l'immédiateté à travers deux besoins fondamentaux du public : l'évasion dans l'imaginaire et la compréhension du monde actuel. En effet, la rapidité des communications, la simultanéité et le temps réel, engendrent un sentiment d'ubiquité, anéantissant la distance physique, morale et les intermédiaires. Le«tout, tout de suite", devient une tendance générale pour un «individu postmoderne enfermé dans son présent, coupé de son passé et ne croyant plus en l'avenir », à qui« l'immédiateté convient lorsqu'il s'agit de la satisfaction de ses désirs » (p. 15). Pour Pascal Josèphe, cette tendance à l'accélération et à la compression du temps positionne l'immédiateté comme le paradigme des techniques numériques et des pratiques sociales contemporaines.

3 Dans une deuxième partie (pp.47-70), il analyse les programmes audiovisuels et explique le développement de la fiction, l'accessibilité sur des supports démultipliés, 
l'essor en parallèle des mondes virtuels et l'omniprésence de la téléréalité en relation avec la tendance du coaching. Pour l'auteur, en multipliant les possibilités d'évasion dans des univers imaginaires par une mise en scène systématique, ces pratiques sont un risque d'affaiblissement des liens entre l'individualisation et le corps social. La priorité est accordée au court terme et à la jouissance immédiate d'un individu décrit comme un hyperactif narcissique, pour qui «l'attente est vécue comme une frustration, un retard, contraire à l'idéal de fluidité généralisée » (p. 71).

Dans une troisième partie (pp.71-132), Pascal Josèphe rappelle comment la société postmoderne aboutit à une valorisation accrue du présent en rejetant le passé, en ne croyant plus dans un hypothétique avenir meilleur:«La mémoire a laissé la place à l'appétit, et l'individu se déplace dans un triangle plaisir/vitesse/oubli, en passe d'être libéré par les nouvelles facilités numériques » (p. 74). Ce rapport au temps influence et bouleverse, semble-t-il, l'ensemble des dimensions de la vie sociale: les médias, la politique, la justice, l'économie, la création, le corps, le sexe, pour tendre vers ce qui est pour l'auteur de l'ordre d'une utopie vouée à l'échec: «Le temps médiatique exerce une pression accrue sur les différents temps sociaux, nourrissant l'utopie communicationnelle du règne de l'immédiat et de l'individu » (p. 72).

Dans une quatrième partie (pp. 133-174), l'analyse traite des liens entre les médias et l'individualisme grandissant. En effet, cette relation particulière qu'impose l'immédiateté fait apparaitre un homme de type nouveau, «l'homo numericus» (p. 139). Face à l'usage des nouveaux médias, il se doit de réagir en permanence et de maîtriser la micro-unité qu'il représente dans un paysage médiatique multiple, délinéarisé, continu et agressif, qui vise davantage « chacun » que la masse : «La société cesse de se définir comme un collectif structuré par les organismes médiateurs, pour devenir un ensemble de micro-unités à l'échelle de l'individu, agitées par un mouvement brownien permanent » (p. 141). Enfin, Pascal Josèphe esquisse la promesse caduque d'une utopie qui revendique la fin de l'Histoire et le passage de la rareté à l'abondance, en portant " en elle le vertige de l'immédiateté, de la transparence, de la dématérialisation et de la déterritorialisation, et l'illusion d'un monde débarrassé de tout ce qui ferait obstacle à la libre spontanéité de l'individu, à son autonomie sans limites » (p. 164).

Dans la partie conclusive (pp. 175-247), l'auteur caractérise «l'hyperindividualisme », le culte de l'immédiat et la fin des projets collectifs au profit d'une revendication permanente des droits individuels qui rend compte de ce qu'il nomme la notion de «postmodernité » (p. 179). Cette postmodernité serait consécutive de l'impossibilité de se référer au passé, et de se projeter dans l'avenir. Seul le présent compte et devient autoréférentiel:«La postmodernité se retrouve comme plongée dans l'instant. L'immédiateté devient une valeur en soi, et le progrès n'est plus mesuré qu'à l'aune de la croissance exponentielle de ses propres critères: toujours plus, et toujours plus vite» (p. 184). L'objectif du plaisir immédiat remplace celui du bonheur, dans une postmodernité qui promeut l'idéologie où le culte de l'individu serait la valeur ultime, conjointeà une inévitable déresponsabilisation généralisée. Pour terminer, Pascal Josèphe met en garde contre le risque que l'hyper-individualisme de l'immédiateté conduise à des dérives totalitaires. Il plaide pour un sursaut des corps intermédiaires qui se devraient de revaloriser des valeurs collectives, par une éthique politique méthodique et structurée.

7 Par un regard percutant, ce livre semble utile à la compréhension d'une époque exacerbée par la révolution numérique et l'immédiateté qu'elle a engendrée. Balayant 
un champ d'investigation large et transdisciplinaire, Pascal Josèphe ne manque pas d'étayer ces propos quelque peu pessimistes ou nostalgiques, de références historiques, philosophiques, psychanalytiques, sociologiques ou scientifiques, qu'il assortit d'une bibliographie généreuse et adaptée. Pourtant, fidèle adepte et figure emblématique du monde des médias, il s'en fait ici le critique virulent à la fois pertinent et impertinent, montrant que cette pression de l'instant conduit à anéantir la notion de projet collectif dans sa forme traditionnelle. Ainsi cet ouvrage invite-t-il à explorer les profonds bouleversements anthropologiques et sociaux qui s'opèrent.

\section{AUTEURS}

GILLES BOENISCH

CREM, Université Paul Verlaine-Metz, gilles.boenisch@wanadoo.fr 